\title{
Forma e Uso Social no Espaço Urbano: Porto Alegre e Recife
}

\author{
Cláudia Loureiro
}

Décio Rigatti

Luis Amorim
Aluna de doutorado - FAUUSP

Aluno de doutorado - FAUUSP

Aluno de doutorado Bartlett School, University College, Londres

\section{Resumo}

Este artigo apresenta os resultados da aplicação de uma teoria descritiva do espaço, desenvolvida por Bill Hillier e seus colegas (1984), ao estudo de duas cidades brasileiras: Porto Alegre e Recife. Os conceitos da teoria da Lógica Social do Espaço (Hillier, Hanson, 1984), e os métodos a eles associados, foram adotados para analisar a morfologia da área central das duas cidades e seus padrōes de apropriação social do espaço. O estudo é também informado pelos conceitos de percurso-matriz e matriz elementar, desenvolvidos por Caniggia, Maffei (1981). This article presents the results of the application of a descriptive theory of the urban space, as proposed by Bill Hillier and colleagues (1984), to study two Brazilian cities: Porto Alegre and Recife. The concepts of the theory of the Social Logic of Space (Hillier \& Hanson, 1984), and its associated methods, are adopted to analyse the morphology of the central area of the two cities and its patterns of social use of the urban space. The study is also informed by the concepts of elementary-matrix and matrix-course, developed by Cannigia \& Maffei (1981), as formative elements of the urban tissue, over and above geometrical order. 


\section{Introdução}

O estudo ora apresentado teve como ponto de partida a leitura do es paço urbano, entendida como o exame do processo tipológico que proporciona a passagem do produto atual, do qual é possível ter uma imediata percepção, à matriz elementar, à qual está submetido, reconstruindo de forma lógica os termos intermediários entre produto atual e sua matriz elementar (Caniggia, Maffei, 1981). Em resumo, o objetivo da análise é explicitar o sistema de leis formativas e de progressiva mutação do tecido urbano, entendido como co-presença, coexistência de edifícios. A técnica selecionada para empreender tal leitura, a análise sintática do espaço (space syntax), tem por meta fornecer um referencial interpretativo com base nos seguintes postulados, conforme proposto por Hillier, Hanson (1984, p. 95):

a. todo assentamento é formado por um sistema contínuo de espaços abertos, cuja forma resulta do arranjo/agrupamento de edifícios (células primárias) e limites secundários (quintais, jardins, etc.) que intervém e se superpõe entre edifícios e o espaço não limitado do assentamento;

b. todo assentamento, visto como uma seqüência de espaços abertos, edifícios (células primárias) e limites secundários, suporta a interface de dois tipos de pessoas que se utilizam do mesmo: os estranhos (ou visitantes) e os habitantes, bem como é palco das relações que se estabelecem entre estas duas categorias - relação entre habitantes do sistema e relação entre habitantes e visitantes.

Calcado neste referencial, o objetivo da análise sintática é o de descrever o assentamento com base no padrão "medido" destas relações através de suas propriedades sintáticas - propriedades que são de natureza topológica e não geométrica. Em outras palavras, o objetivo é descrever como o sistema como um todo se relaciona a cada uma de suas partes constituintes, e como a multiplicidade destas relações produz uma estrutura subjacente (Peponis, 1992).

$O$ estudo aqui apresentado toma por base dois argumentos:

a) a descrição da maneira pela qual cada espaço é acessado, a partir de todos os outros espaços do sistema urbano, é chave para entender a tipologia espacial urbana. Esta descrição é dada pelo número de mudanças de direção necessárias para se alcançar determinado espaço, ou seja, diz respeito aos padrōes de acessibilidade ou permeabilidade do sistema espacial considerado, e à maneira pela qual o arranjo de edificações e entradas controla o acesso e movimento de pessoas e veículos de e para o espaço aberto.

b) tal estrutura de acessibilidade está associada e é, em grande medida, determinada pelos percursos-matriz e pela matriz elementar da fração urbana. $A$ matriz elementar é identificada como termo limite de um processo formativo, tomado como inicial por sua virtude de poder ser reconhecido como necessário momento na formação de tipos sucessivos. A idéia de matriz elementar se associa à noção de percurso-matriz. Percurso é entendido como estrutura de relações entre lugares. A formação de um percurso pode ser autônoma com relação ao uso de suas margens por edificações - como o percurso que interliga dois pólos, sem ter sido utilizado anteriormente para acesso a edificações. Tal percurso é dito percurso-matriz-um percurso preexistente, cujo desenvolvimento independe da localização de edificações em suas margens e que, na mediação entre lugares, cumpre a exigência de ser retilíneo, para fazer mais curto o trajeto, à exceção da necessidade de superar obstáculos, quer sejam naturais ou antrópicos (Caniggia, Maffei, 1981, p. 60, 132). 


\section{A Descrição do Leiaute Urbano}

Uma das dimensões mais importantes da tipologia urbana refere-se à relação de padrōes locais e padrões globais. Na análise sintática, estas dimensões podem ser objetivamente medidas através das propriedades sintáticas do tecido urbano, tomando por base sua organização global. Para efeitos de análise, esta organização global é representada através de um instrumento que torna as relações entre estruturas locais e globais melhor apreensíveis que as formas tradicionais de representação do urbano - o mapa axial. O mapa axial é a representação da configuração dos espaços abertos e contínuos da malha urbana através de suas linhas de acessibilidade - as linhas axiais - e de suas conexōes. Na figura 1, um assentamento hipotético é representado de duas formas: à esquerda, na forma tradicional de representação, com os espaços abertos e contínuos marcados em preto, e à direita, a tradução desta representação em um mapa axial desta área. A representação axial da malha urbana traduz, desta forma, a representação do movimento para e através do sistema. A partir desta representação, instrumentochave da análise, se obtém as medidas objetivas descritas a seguir.

\section{As Medidas Sintáticas}

\section{Integração/Núcleo de Integração}

A medida de integração é chave na análise sintática. O conceito de integração está relacionado à noção de profundidade. Na representação axial do sistema urbano, que mapeia a acessibilidade e conexões de todas as linhas axiais, ou espaços, cada linha está ligada a todas as demais tanto diretamente quanto por meio de um certo número de linhas intervenientes, ou "passos" que intermediam a passagem de um espaço a outro. A profundidade entre duas linhas é dada pelo número de passos que intervém na passagem da primeira para a segunda. Na Fig. 1, a profundidade entre as linhas $A$ e $B$ que se interceptam é 1, assim como a profundidade entre $\mathrm{A}$ e $\mathrm{C}$. Tomando a linha $\mathrm{A}$ como referência, nos demais casos, a profundidade é medida pelo número mínimo de linhas que devem ser cruzadas

Figura 1

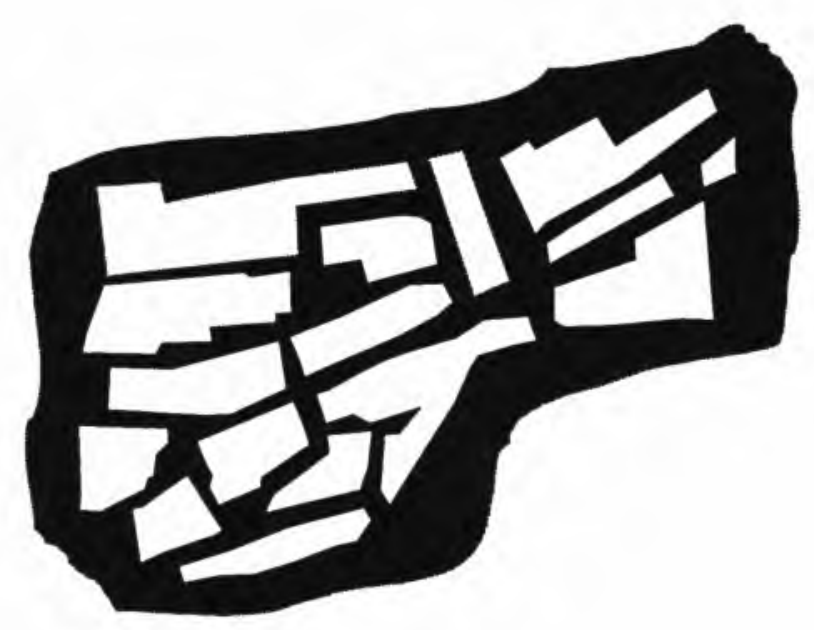

Estrutura do espaço aberto

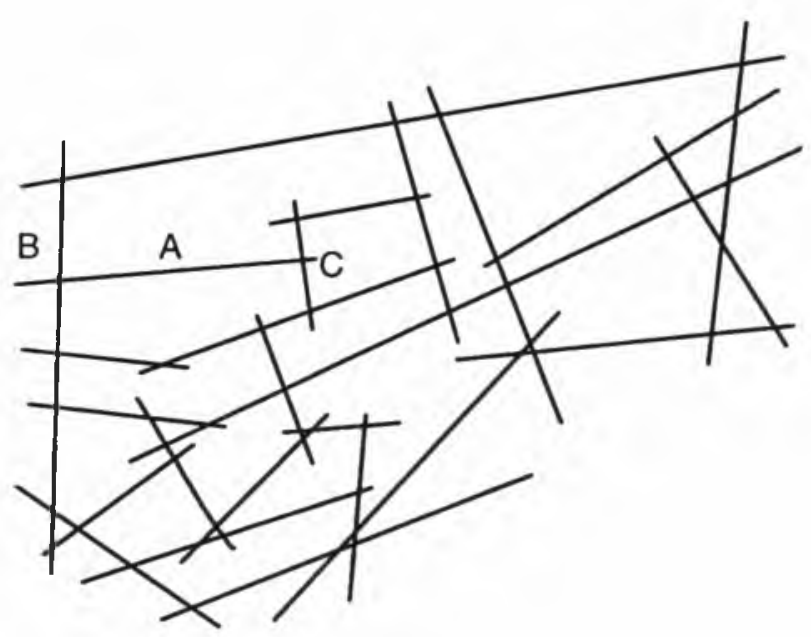

Estrutura do espaço aberto, traduzida em estrutura axial - o mapa axial 
para, partindo da linha $A$, atingir uma outra qualquer do conjunto: uma linha tem profundidade 2 , em relação à linha raiz, se há uma linha extra intervindo na passagem de uma para outra, e assim por diante. Uma linha "rasa" tem por efeito "puxar" para si todas as demais, integrando o conjunto - assim sendo, quanto menor a profundidade de uma linha axial, mais integrada é esta linha, possuindo acessibilidade mais direta a partir de qualquer ponto do conjunto. Por sua vez, uma linha profunda afasta de si todas as demais, resultando em um espaço mais segregado do conjunto, ou seja, de acessibilidade menos direta (Hillier, Hanson, Peponis, 1987; Hillier, 1989; Teklenburg, Timmermans, van Wagenberg, 1991).

O valor de integração é, matematicamente, a expressão da profundidade de cada linha a partir de todas as outras do sistema, ou seja, expressa a relação entre a profundidade média de cada linha axial e o número total de linhas que conformam o conjunto, conforme a expressão abaixo, onde I representa o valor de integração da linha considerada, MD, a profundidade média da linha em relação a todas as demais do sistema, e $L$, o número total de linhas do sistema:

$$
I=2(M D-1) /(L-2)
$$

O valor de integração, varia de 0 a 1 . Os sistemas mais rasos, ou de maior integração, com valor de integração médio igual ou próximo a zero, são aqueles em que todos os espaços se ligam diretamente a um ponto de origem, exterior ao assentamento. Os sistemas mais profundos, ou mais segregados, com valores de integração próximos a 1, têm seus espaços organizados de forma seqüencial a partir de um ponto de origem, cada espaço adicionando ao sistema mais um nível de profundidade (Figs, 2a e 2b).

Para permitir a comparação entre sistemas de diferentes tamanhos, o valor de integração do sistema real é relacionado ao valor de integração de um sistema de mesmo número de espaço, em forma de diamante, expressando a profundidade teórica deste sistema (Hillier, 1989; Teklenburg, Timmermans, van Wagenberg, 1991). Um sistema com esta forma tem $n$ nós no nível de profundidade médio, $n / 2$, um nível abaixo e acima do nível médio, $n / 4$, nos níveis acima e abaixo do nível $n / 2$, e assim por diante, até o nível mais profundo, com um nó. Nesta representação, - nó designa as linhas do mapa axial, enquanto as linhas que unem os nós, designam as intersecções entre linhas. Com esta correção, os valores da propriedade integração são crescentes a partir de zero, sendo que menores valores indicam sistemas de menor profundidade e valores superiores a 1 , sistemas mais profundos (Teklenburg, Timmermans, van Wagenberg, 1991).

sistema de profundidade

mínima

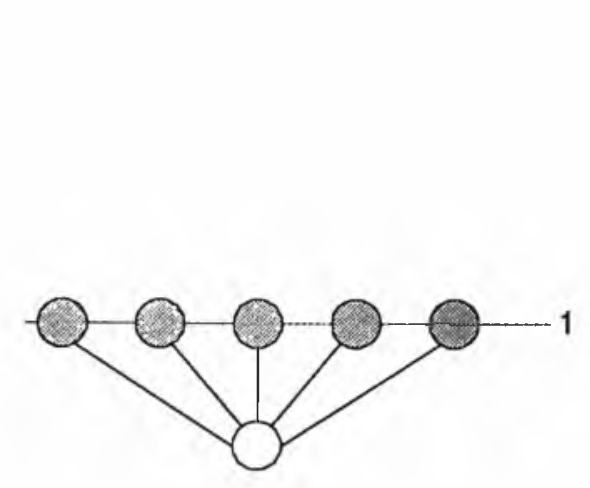

Figura $2 a$

\section{Figura $2 b$}

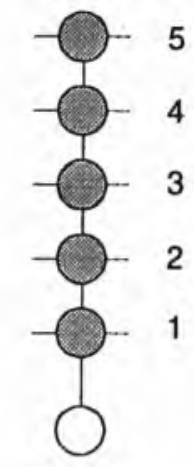

seqüência linear de espaços: profundidade máxima
A

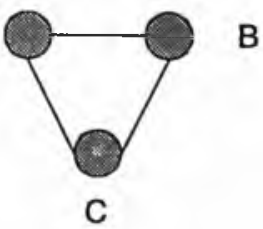

relação de simetria

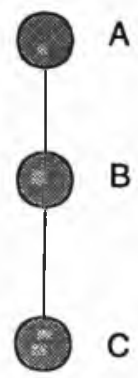

relação de assimetria 
A condição de integração espacial está relacionada à noção de simetria/assimetria de uma dada morfologia, que trata da relação de dois espaços com um terceiro. Uma descrição é dita simétrica quando a relação entre dois espaços for igual para ambos, assim como é a de ambos para um terceiro. Na figura $2 b$, a relação de A para $B$ é simétrica, assim como as relações de ambos com $C$. Na figura $2 b-$ a relação de $A$ para $B$ com relação a $C$ não é a mesma que a relação de $B$ para $A$, dado que $B$, intermedia a passagem de $A$ para $C$. Este tipo de relação é dita assimétrica (Hillier, Hanson, 1984, p. 94).

O sentido sociológico da simetria/assimetria diz respeito às relações que se estabelecem no espaço urbano. Segundo Hillier, Hanson (1984), há uma maior tendência à integração entre diferentes categorias sociais em descrições simétricas, enquanto que a assimetria estaria relacionada a uma maior segregação entre estas categorias. Evidências empíricas sugerem uma relaçāo entre a propriedade de integração tal como definida e padrões de movimento, ou, melhor dizendo, entre esta propriedade e a previsibilidade de movimento. Desta forma, uma vez que os espaços mais integrados são aqueles onde há uma maior probabilidade de movimento e de encontro entre habitantes em movimento e visitantes, as atividades dependentes de movimento e de relaçōes espaciais estariam ai localizadas, enquanto que as áreas espacialmente mais segregadas seriam primariamente residenciais, locus de relações transpaciais.

De particular interesse, tanto do ponto de vista teórico quanto empírico, são as propriedades do núcleo de integração, que compreende os espaços mais facilmente acessiveis, ou melhor integrados no leiaute urbano como um todo. Particularmente, o padrão formado pelas linhas, ou espaços mais integrados é uma propriedade relevante. De uma maneira geral, o núcleo formado por $10 \%$ das linhas mais integradas é suficiente para a análise, em conjuntos com mais de 100 linhas axiais, ou $25 \%$, para conjuntos menores. As linhas do núcleo têm o papel de estabelecer a ligação de espaços situados na periferia com espaços centrais. A forma do núcleo de integração varia de sis tema a sistema, no entanto, de uma maneira geral, ela se aproxima à forma de uma roda de bicicleta, com um centro, raios que partem deste núcleo central em várias direçōes e um anel periférico. Esta estrutura pode se apresentar mais ou menos deformada, ou mais ou menos completa (Hillier, Hanson, 1984; Hillier, Hanson \& Peponis, 1987).

\section{Força do núcleo de integração}

Ainda relacionada ao núcleo de integração, outra relevante propriedade é a força deste núcleo, que numericamente expressa a relação entre o valor de integração média da área como um todo e o valor de integração média dos espaços que compõem o núcleo. Este valor traduz a diferença de grau de integração entre os espaços que compõem o núcleo e os espaços da área como um todo: quanto maior a diferença entre estes valores, mais o núcleo se caracteriza como o centro sintático da área (Peponis et al., 1989).

\section{Inteligibilidade}

A inteligibilidade de uma área é definida como o grau de correlação entre o número de conexões e o valor de integração de cada linha. Quanto maior a correlação (maior inteligibilidade) mais se pode inferir a posição global de um espaço a partir de suas conexões locais diretamente observáveis, ou seja, a propriedade de inteligibilidade refere-se à capacidade de se obter informações globais a partir de informaçōes locais (Hillier, 1989; Peponis, 1989). 


\section{Axialidade da malha}

Esta medida traduz a comparação entre a malha real e uma malha regular, expressando o grau de deformação axial, conforme expressão abaixo. É função do número de linhas do sistema e do número de ilhas espaciais formadas por estas linhas. Ilha espacial é definida como o bloco de edifícios continuamente conectados, totalmente envolvido por espaços abertos. Numa malha regular, a axialidade é 1; valores tendendo para zero indicam forte deformação da malha. $\mathrm{Na}$ expressão abaixo, A é a medida de axialidade da malha urbana, $\mathrm{S}$, é o número de ilhas espaciais do sistema, e $L$, o número de linhas axiais.

$$
A=\left[\left(\sqrt{ } S^{*} 2\right)+2\right] / L
$$

\section{Apresentação dos Casos}

\section{Porto Alegre - Rio Grande do Sul}

A cidade de Porto Alegre situa-se no extremo Sul do Brasil, à beira de um estuário onde se forma o Rio Guaíba. Sua fundação data de meados do século 18, quando já existiam algumas áreas ocupadas na regiāo e com as quais Porto Alegre se comunica através de diversos caminhos.

Sua estrutura urbana inicial foi fortemente influenciada por sua característica de península e na forma de relação com a região, através de caminhos. Apesar do terreno acidentado, o traçado urbano é bastante regular, fugindo da tradição dos traçados portugueses e aproximando-se das concepçōes espanholas muito embora, à época do início da formação de Porto Alegre, essas características não sejam mais utilizadas de forma tão rígida, sendo que a regularidade de traçado também passa a ser utilizada em áreas de ocupação portuguesa.

O período de análise foi definido a partir da disponibilidade de cartografia e pelas alterações apresentadas na estrutura urbana no processo de crescimento urbano. Assim, a área mais central é examinada em 1839, 1888, 1935 e 1993.

\section{Recife, Pernambuco}

A análise para Recife compreendeu 244 anos de sua história, de 1749 a 1993. A área analisada abrange os atuais bairros do Recife e de Santo Antônio/São José, correspondentes ao sítio ocupado nos dois primeiros séculos, a partir da instalação da primeira ermida da povoação conhecida como "Povo do Arrecife" A escolha do período analisado foi norteada pelos critérios de disponibilidade de material cartográfico e o de marcos significativos no processo de urbanização.

\section{Resultados}

Os resultados expostos a seguir estão apresentados em tabelas, coma transcrição dos resultados das medidas sintáticas representativas da estrutura global de cada momento analisado, obtidos através de programa de computador específico'. bem como, através da representação axial dos planos para Porto Alegre e para

(1) Os resultados das medidas sintáticas foram obtidos utilizando-se os programas de computador AXIAL 2.0, desenvolvido por André Bergholz e Cristina Gobbie AXIAL 3.0, por Luciano Domenico Giordana, sob coordenação do prof. Frederico Holanda, da Universidade de Brasflia. Recife. Os mapas axiais mostram o núcleo de integração, formado por $10 \%$ das linhas mais integradas do sistema espacial considerado, e o conjunto de $50 \%$ de espaços mais segregados, de forma a permitir a análise do padrāo de acessibilidade e articulação da estruturas locais, a partir da distribuição de integração e de segregação. 


\section{Resultados para Porto Alegre}

As medidas sintáticas obtidas para Porto Alegre nos anos considerados constam da tabela abaixo. A redução do valor de integração média, I médio, indica um processo de transformaçāo espacial, decorrente das reformas urbanas executadas, que reforça a integração entre as diversas partes do tecido urbano da área central de Porto Alegre. A comparação entre os valores de integração e os de inteligibilidade aponta, por sua vez, para um processo onde, apesar do aumento da acessibilidade entre os espaços, suas propriedades locais e diretamente observáveis reduzem seu papel como guia para a compreensão do todo. Este fato é reforçado pela redução, ao longo do período, dos valores de axialidade da malha, tendendo para forte deformação da mesma. Esta maior deformação enfatiza a estrutura de organização local, em detrimento da organização global do espaço urbano.

Valores das propriedades sintáticas para Porto Alegre, em função do período analisado

\begin{tabular}{l|l|l|l|l|l|l|l}
\hline Ano & No Linhas & № Ilhas & $\begin{array}{l}\text { Profund. } \\
\text { Média }\end{array}$ & I médio & Axialidade & $\begin{array}{l}\text { Inteligibili- } \\
\text { dade }\end{array}$ & $\begin{array}{l}\text { Força do } \\
\text { Núcleo }\end{array}$ \\
\hline 1839 & 90 & 80 & 4,3950 & 0,8479 & 0,2210 & 0,6249 & 1,52 \\
\hline 1888 & 118 & 121 & 6,2545 & 0,6742 & 0,2034 & 0,5939 & 1,41 \\
\hline 1935 & 188 & 247 & 3,8458 & 0,5667 & 0,1778 & 0,6212 & 1,43 \\
\hline 1993 & 295 & 310 & 4,1064 & 0,5580 & 0,1261 & 0,5757 & 1,40 \\
\hline
\end{tabular}

Os valores decrescentes de força do núcleo de integração indicam uma redução progressiva do papel do núcleo de integração inicial como núcleo sintático da área e corresponde ao surgimento de subcentros, conectados entre si, onde ocorre uma complexidade maior do ponto de vista das funções urbanas atualmente existentes.

Do ponto de vista dos núcleos de integração e dos espaços de segregação, temos (Figs. 3 a 6):

\section{a. 1839}

Os espaços mais integrados são interiores às trincheiras de proteção da cidade e o núcleo de integração é definido basicamente a partir da penetração à área central e pelos acessos aos caminhos que levam a outras regiões - rua da Praia (1), atual rua dos Andradas; rua Formosa (2), atual av. Duque de Caxias; rua do Arvoredo (3), atual rua Fernando Machado e rua da Ponte (4), atual rua Riachuelo - unificadas pela rua de Bragança (5), atual rua Marechal Floriano, rua do Rosário (6), atual rua Vigário José Inácio e rua da Ladeira (7), atual rua General Câmara. O núcleo de integração apresenta a forma de uma "roda de bicicleta". deformada e incompleta, sem a presença de anel periférico e raios partindo do núcleo em diversas direçōes, à exceção da linha 1, que articula ao núcleo espaços de relativa profundidade, ou segregados espacialmente. Esta estrutura do núcleo de integração irá nortear todo o processo de crescimento urbano posterior. Os 
espaços mais segregados ocorrem em setores ao longo do cais e na extremidade sul da península. A presença de uma série de becos com fracas conexōes com o entorno define esses espaços segregados.

\section{b. 1888}

Em decorrência da eliminação das trincheiras, a cidade se expande para fora dos limites até então ocupados. O núcleo de integração claramente enfatiza os acessos ao centro, através de algumas das linhas anteriormente identificadas (linhas 1, 4, 2, 5), acrescidas da estrada do Mato Grosso, trecho da atual av. João Pessoa (8), da Estrada do Meio, atual av. Osvaldo Aranha (9) e pela rua Coronel Genoíno (10). A concentração de linhas de maior integração na área correspondente aos portōes da antiga fortificação, demonstra sua importância na estruturação da área central da cidade. Quanto à forma do núcleo de integração, é mantida a estrutura em "roda deformada" descrita para o período anterior, que se acresce de um número maior de linhas integradas que buscam áreas periféricas. $E$ interessante notar o surgimento de um segundo centro, mesmo que de forma ainda incipiente, formado de espaços que cumprem a função de acessar o núcleo primitivo a partir dos caminhos existentes no sul da península. Desta forma, o núcleo principal passa a se articular a um segundo, através de um eixo que pertence simultaneamente aos dois núcleos, que é a rua Silva Tavares (5) - atual rua Marechal Floriano, o que vem reforçar seu papel integrador.

Figura 3

Porto Alegre - 1839

Acima, sistema de espaços abertos, em preto.

Abaixo, mapa axial, com núcleo de integração marcado emnegrito éareas segregadas, em cinza
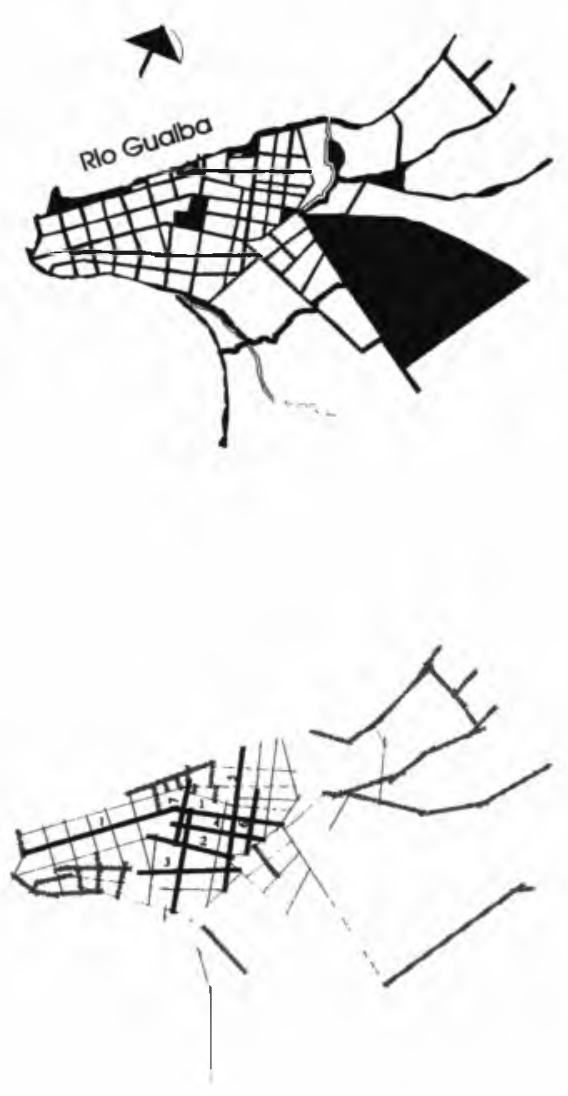

Figura 4

Porto Alegre - 1888

Acima, sistema de espaços abertos, em preto.

Abaixo, mapa axial, com núcleo de integração marcado em negrito eáreas segregadas, em cinza
Figura 5

Porto Alegre - 1935

Acima, sistema de espaços abertos, em preto. Abaixo, mapa axial, com núcleo de integração marcado em negrito eáreas segregadas, em cinza
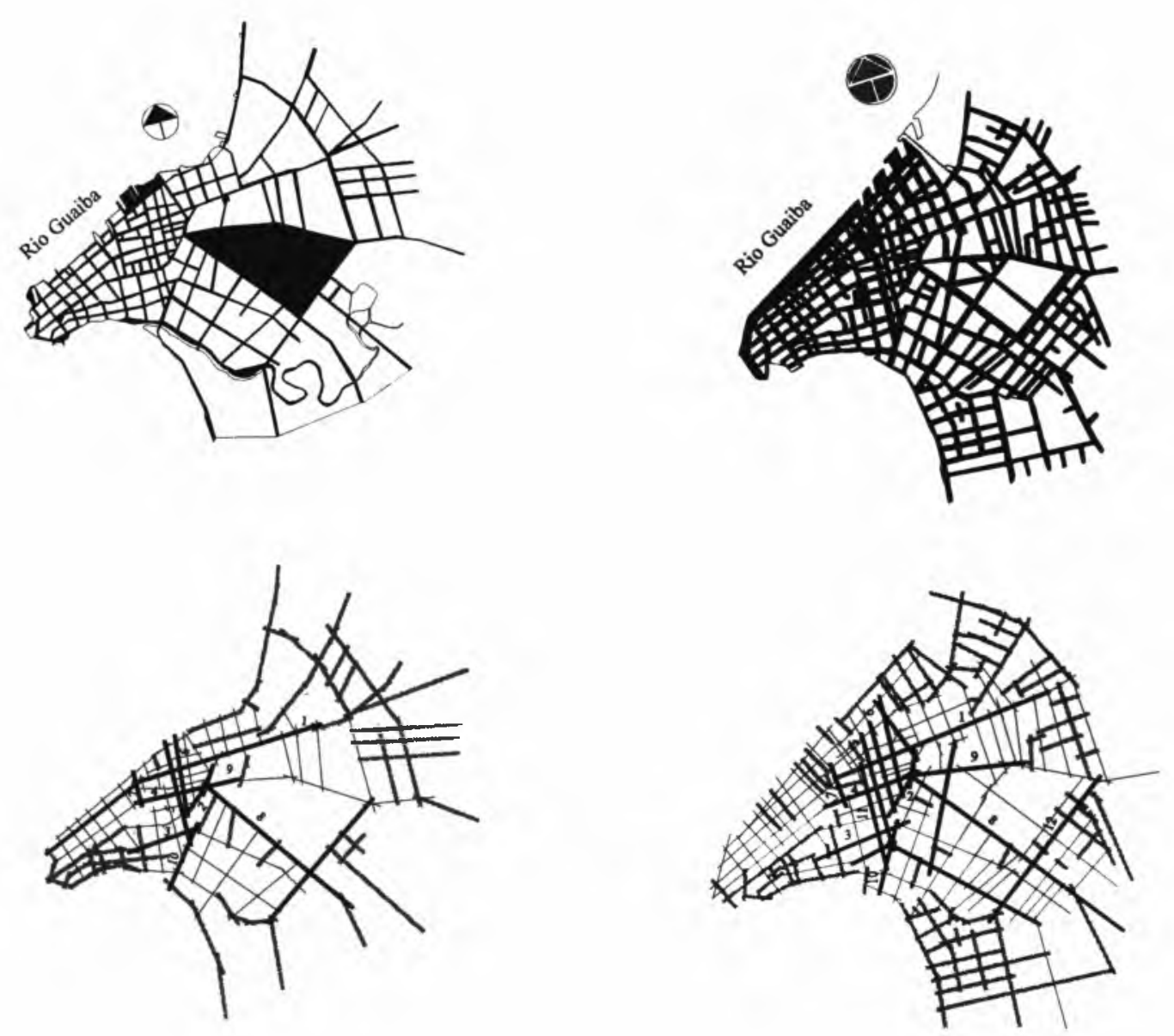
Quanto aos espaços mais segregados, além dos eixos mais periféricos, estes se concentram na extremidade sul da península, como no período anterior. As obras de aterros e reformulações ao longo do cais, na parte norte da península, vai integrando esses espaços de forma mais acentuada, deixando de se constituir emáreas de maior segregação, como ocorria até então. A encosta sul permanece fora da área de interesse para as intervenções urbanas mantendo seu grau de segregação espacial. Desta forma, enquanto a encosta norte vai concentrando as atividades de comércio e de serviços, sobretudo, na encosta sul expande-se a atividade residencial.

\section{c. 1935}

Neste período, além da grande expansão para fora do núcleo inicial, o centro da cidade apresenta uma série de reformas urbanas, oriunda de diversos planos. Abrem-se várias avenidas e alargam-se e prolongam-se outras já existentes. A estrutura básica do núcleo de integração, no entanto, permanece quase que inalterada, denotando o papel que as estruturas anteriores desempenham no processo de crescimento urbano. Os antigos caminhos transformam-se em avenidas (linhas 1, 9, 8), criam-se novas (linhas 11 e 12). Os caminhos que formavam o núcleo de integração, agora de forma mais evidente do que já acontecia em 1888, além de se constituírem em percursos-matriz no sentido de que ligam o pólo do centro de Porto Alegre com outros pólos próximos, atuam

Figura 6

Porto Alegre - 1993

Acima, sistema de espaços abertos, em preto. Abaixo, mapa axial, com núcleo de integração marcado em negrito e áreas segregadas, em cinza
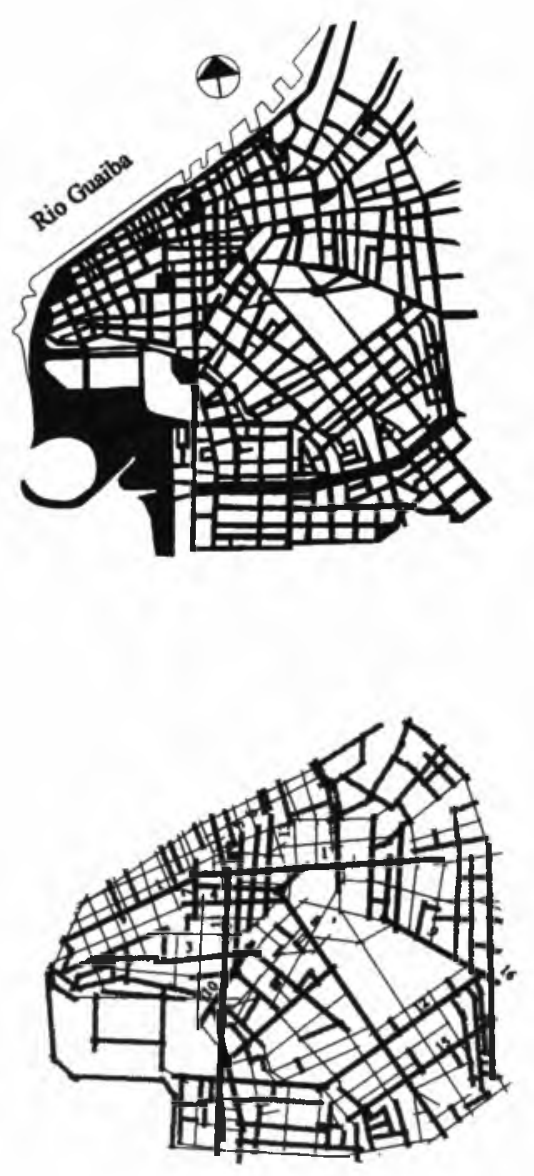

Figura 7

Recife - 1749

Acima, sistema de espaços abertos, em preto. Abaixo, mapa axial, com núcleo de integração marcado em negrito e áreas segregadas, em cinza
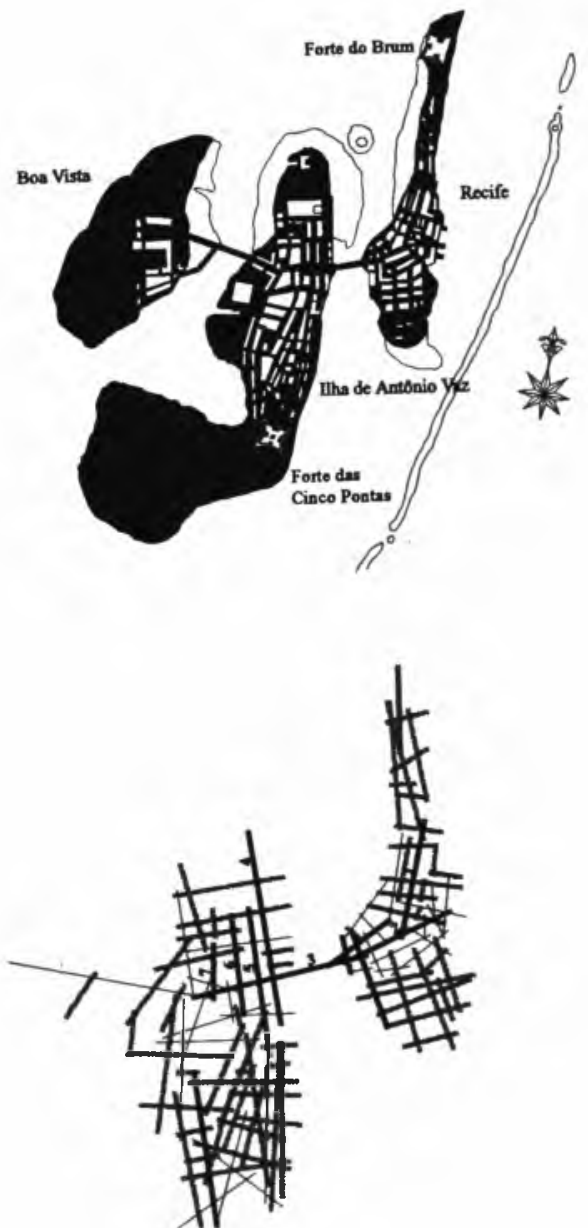

Figura 8

Recife - 1906

Acima, sistema de espaços abertos, em preto. Abaixo, mapa axial, com núcleo de integração marcado em negrito eáreas segregadas, em cinza
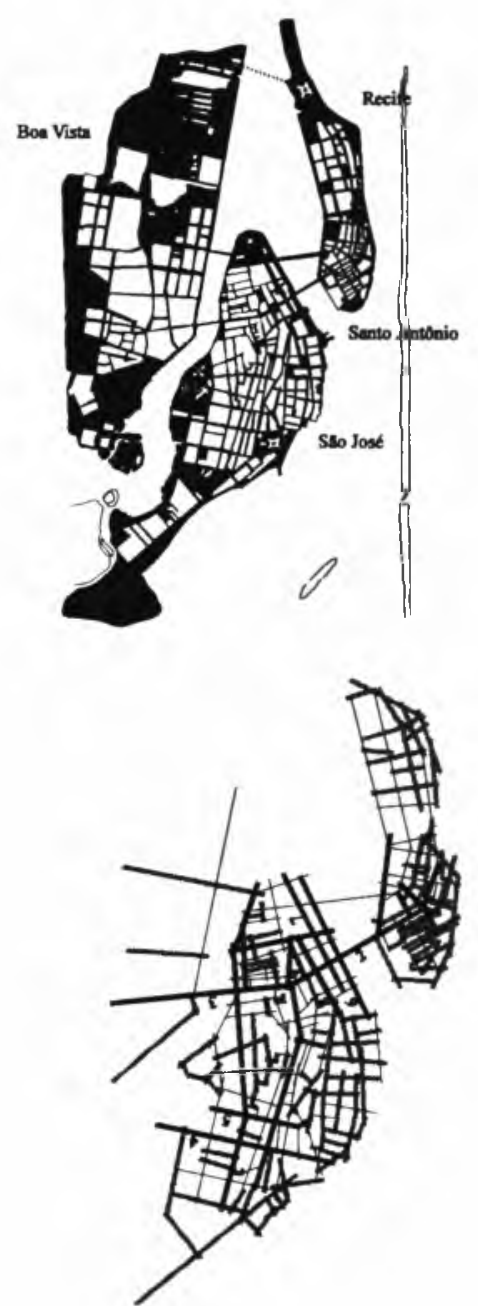

Pós - R. Prog. Pos-Grad. Arquit. Urb. FAUUSP, São Paulo, n.5 p. 17-31 abr. 1995 
como percurso-matriz na consolidação da ocupação que ocorre, primeiramente, ao longo desses percursos e, logo em seguida, orientando as formas de parcelamento e ocupação urbana a partir desses percursos.

O núcleo de integração permanece formado pelos antigos caminhos, ligado por outros espaços que fazem a unificação desse núcleo percebendo-se, ainda em 1935, a força de estruturação urbana em torno da antiga fortificação e portões. Consolida-se, neste momento, um processo que no período anterior havia se insinuado, qual seja o da existência de um núcleo de integração presente desde - início da formação da cidade, que denominamos de núcleo principal, e um segundo núcleo, mais ao sul, que agora se estrutura de uma maneira mais evidente, mantendo-se articulado ao núcleo principal por alguns eixos.

A área de maior segregação, afora as periféricas decorrentes do processo de crescimento urbano, permanece sendo a extremidade sul da península. Além dessas, uma série de travessas abertas perpendicularmente ao cais, também vão constituir os espaços mais segregados, num momento de grandes transformações com a construção do porto.

\section{d. 1993}

As extensas reformas urbanas que ocorrem na cidade entre 1935 e 1993, que na área central refletem-se particularmente na abertura das avenidas perimetrais e na construção de amplas áreas de aterro ao sul, confirmam, via de regra, o núcleo de integração presente em períodos anteriores. Desta forma, rua dos Andradas e av. Independência (1), av. Osvaldo Aranha (9), av. João Pessoa (8), rua Riachuelo (4), av. Borges de Medeiros (11), mantêm-se como espaços de maior integração, juntamente com eixos de articulação entre eles, como a rua Marechal Floriano (5), av. Venâncio Aires (12), rua Dr. Flores (13) e av. Ramiro Barcelos (14). Das novas perimetrais, apenas um dos seus trechos se configura como de maior integração e os amplos aterros que se ligam à antiga extremidade sul da península possuem uma ordem de organização espacial que mantém e amplia o grau de segregação desse tecido.

O exame da forma do núcleo de integração parece apontar para um reforço no processo de formação de subnúcleos articulados entre si, o que já podia ser constatado, num processo inicial, ainda nos dados de 1888 . Fica evidenciado que o processo de crescimento do tecido urbano foi estruturando núcleos de integração secundários para além do núcleo de integração principal, o qual corresponde ao núcleo de integração inicial. O subnúcleo ao sul da península parece confirmar e ampliar sua importância, ao mesmo tempo em que é possível identificar outro subnúcleo que se forma nas proximidades do cruzamento da av. Venâncio Aires (12) e av. Jerônimo de Ornelas (15) com a av. Osvaldo Aranha (9), av. Protásio Alves (16) e av. Ramiro Barcelos (14). Associando-se estas observações com a atual distribuição das funções urbanas, percebe-se que estes subnúcleos representam áreas de concentração de atividades comerciais e de serviço, atuando como verdadeiros centros de bairro. No que se refere aos espaços de maior segregação, mantém-se a tendência verificada nos períodos anteriores.

\section{Resultados para Recife}

Os resultados obtidos para os parâmetros sintáticos analisados estão expostos na tabela ao lado. 
De uma maneira geral, a área analisada evolui ao longo do tempo para um conjunto mais integrado, indexando a acessibilidade de cada espaço em particular como destinação para todos os outros do sistema. A força do núcleo de integração cresce ao longo do período entre 1906 e 1993, reforçando o seu papel como centro sintático do conjunto. Do ponto de vista da regularidade da trama, esta se torna mais deformada nos dois momentos intermediários da análise, apresentando uma tendência à maior regularidade no último, quando os efeitos das reformas urbanas modernas se consolidam. Esta tendência, no entanto, não resulta em maior inteligibilidade, cujo valor volta a sofrer um decréscimo após estas reformas, indicando um processo em que o aumento de acessibilidade leva à perda da capacidade de se obter informaçōes globais a partir de propriedades locais.

Valores das propriedades sintáticas para Recife, em função do período analisado

\begin{tabular}{l|l|l|l|l|l|l|l}
\hline Ano & $\begin{array}{l}\text { Linhas } \\
\text { Axiais }\end{array}$ & Ilhas & $\begin{array}{l}\text { Profund. } \\
\text { Média }\end{array}$ & I médio & Axialidade & $\begin{array}{l}\text { Inteligibi- } \\
\text { lidade }\end{array}$ & $\begin{array}{l}\text { Força do } \\
\text { Núcleo }\end{array}$ \\
\hline 1749 & 104 & 110 & 3,931 & 0,745 & 0,220 & 0,565 & 1,482 \\
\hline 1906 & 214 & 207 & 4,452 & 0,641 & 0,143 & 0,643 & 1,381 \\
\hline 1932 & 188 & 192 & 4,137 & 0,616 & 0,158 & 0,606 & 1,374 \\
\hline 1993 & 174 & 180 & 4,034 & 0,616 & 0,165 & 0,575 & 1,484 \\
\hline
\end{tabular}

Comparando a organização dos núcleos de integração e áreas segregadas, através dos mapas axiais representados nas Figs. 7 a 10, podemos destacar:

\section{a. 1749}

O núcleo de integração, formado por 11 linhas, é estruturado em dois subcentros: o da zona portuária, no istmo, e o da ilha Antônio Vaz, este último correspondendo ao antigo bairro holandês - o "Groot Kwartier" parte da estrutura urbana implantada pelo Conde Maurício de Nassau, no século 17, por ocasiāo da ocupação holandesa (linhas $4,5,6,7$ ). O percurso inicial, que unia as portas da povoação primitiva, permanece, se prolongando, através da rua da Cadeia (2), ao lado da matriz do Corpo Santo, até a praça do Pelourinho, passo de embarque e desembarque de mercadorias, se consolida como percurso-matriz, sendo a linha mais integrada do conjunto. Este percurso se prolonga na direção leste/oeste cortando a itha transversalmente (3), sendo as demais linhas do núcleo perpendicular a ele.

Os espaços mais segregados estão distribuídos em agrupamentos localizados na periferia da área. Na ilha Antônio Vaz, correspondem à ocupação portuguesa pós período holandês, caracterizada por uma malha extremamente irregular, centrada na localização das igrejas, com seus pátios e adros ladeados por ruas estreitas e tortuosas. No istmo, estes espaços se localizam fora de portas, ao norte, em área ocupada basicamente por armazéns de estocagem de mercadorias, e na extremidade sul do istmo, sobre área anteriormente alagada, esta destinada à habitação. 
Com a ocupação de novas áreas aterradas, o aumento do número de linhas axiais e de ilhas que formam o conjunto (214 linhas e 207 ilhas), tornam a malha mais deformada em relação ao momento anterior, enquanto há um processo de adensamento do núcleo de integração, formado por 24 linhas, que corresponde a $11.2 \%$ do total.

O subnúcleo de integração da ilha Antônio Vaz, neste período organizada em dois bairros - Santo Antônio e São José, se torna mais contínuo e difuso, alongandose na direção sul, com surgimento de algumas linhas transversais no sentido leste/oeste (linhas 4 e 5). Esta estrutura forma um anel que envolve e conecta as principais igrejas. Este alongamento do núcleo tem por efeito, ainda, uma maior articulação dos espaços segregados ao sul com o percurso-matriz. Como foco central do núcleo de integração permanecem as linhas que correspondem ao antigo bairro holandês (linhas $6,7,8$ e 9). No Recife, um maior número de linhas passa a fazer parte do núcleo, formando um subnúcleo em torno da igreja do Corpo Santo.

A passagem para a Boa Vista (3) é reforçada, prolongando o percurso inicialmente identificado na direção da matriz da Boa Vista.

O núcleo segregado se torna menos denso (126 linhas) - os espaços segregados se tornam mais dispersos ao longo do conjunto. Basicamente os espaços mais segregados se concentram na ilha do Recife, sobretudo nas áreas ganhas ao mar e ao rio através de aterros, compondo novas quadras destinadas a armazéns.

\section{c. 1932}

Este momento retrata a cidade após a primeira das grandes intervenções urbanas realizadas na área ao longo do século 20. Esta intervenção, fundamentada em princípios urbanísticos haussmanianos, provoca uma ruptura no tecido português. Duas longas avenidas ( 1 e 2), radialmente dispostas a partir do ponto que se convencionou chamar de marco zero, se prolongam até a ilha de Antônio $\mathrm{Vaz}$, formando um polígono que envolve os dois subcentros anteriormente identificados, aonde se localizam as instituições públicas e financeiras. Com esta nova configuração, aumenta a distributividade do núcleo, passando acesso e movimento a serem menos controlados.

Como conseqüência desta intervenção, atenua-se a tendência de penetração do núcleo para o sul do bairro de São José, provocando ainda uma ruptura no anel que envolvia as edificações religiosas.

\section{d. 1993}

A área é objeto de mais duas grandes intervençōes urbanísticas que, além do sentido funcionalista, tem caráter de monumentalidade - a av. Guararapes (7), na década de 40 e a av. Dantas Barreto (linhas 5 e 6) na década de 70 . As duas novas avenidas se agregam ao núcleo de integração, agora mais concentrado na ilha de Antônio Vaz, tornando o bairro do Recife espacialmente mais segregado do conjunto. Esta configuração espacial reforça o papel de centro sintático da área dos espaços mais integrados da llha de Antônio Vaz, enquanto que, praticamente, elimina deste núcleo os espaços que compunham o subcentro da área portuária, observado nos momentos anteriores. O núcleo, neste momento, torna-se mais distributivo. 


\section{Discussão}

De uma maneira geral, as intervençōes urbanas implantadas nas duas cidades têm por efeito tornar o conjunto mais integrado como um todo, ocorrendo, no entanto, perda de inteligibilidade. Isto significa dizer que enquanto tais transformaçōes levam a um aumento da acessibilidade do conjunto, reforçando seu papel como destinação coletiva, há uma diminuição do papel de estruturas locais para a compreensão do todo.

Examinando-se a evolução da organização dos núcleos de integração e os espaços segregados para a área central de Porto Alegre, podemos resgatar os seguintes aspectos:

a) o conjunto da área apresenta um processo de transformações morfológicas que acentua a integração entre suas partes, significando um aumento de acessibilidade entre os diversos espaços componentes do tecido, ampliando as condições de integração de categorias sociais;

b) os caminhos de ligação do núcleo inicial da cidade com cidades vizinhas constituem um sistema de espaços de maior integração que se mantêm ao longo do tempo. Esses caminhos operam como percursos-matriz, tanto no sentido de estabelecer relaçōes entre pólos urbanos distintos, como no de atuar como matriz de crescimento, condicionando a organização do futuro tecido urbano;

c) de um leiaute inicial que poderia ser considerado regionalizado do tipo que corresponde à convergência das partes a um centro comum, podemos verificar

Figura 9

Recife - 1932

Acima, sistema de espaços abertos, em preto.

Abaixo, mapa axial, com núcleo de integração marcado em negrito e áreas segregadas, em cinza
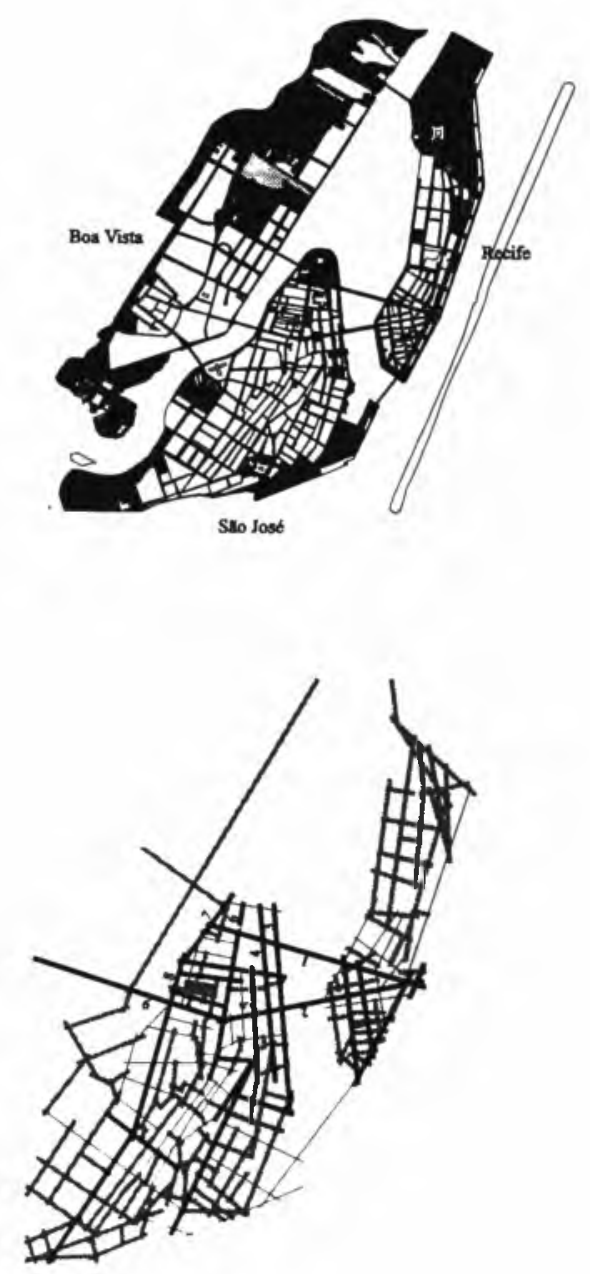

Figura 10

Recife - 1993

Acima, sistema de espaços abertos, em preto.

Abaixo, mapa axial, com núcleo de integração marcado em negrito e áreas segregadas, em cinza
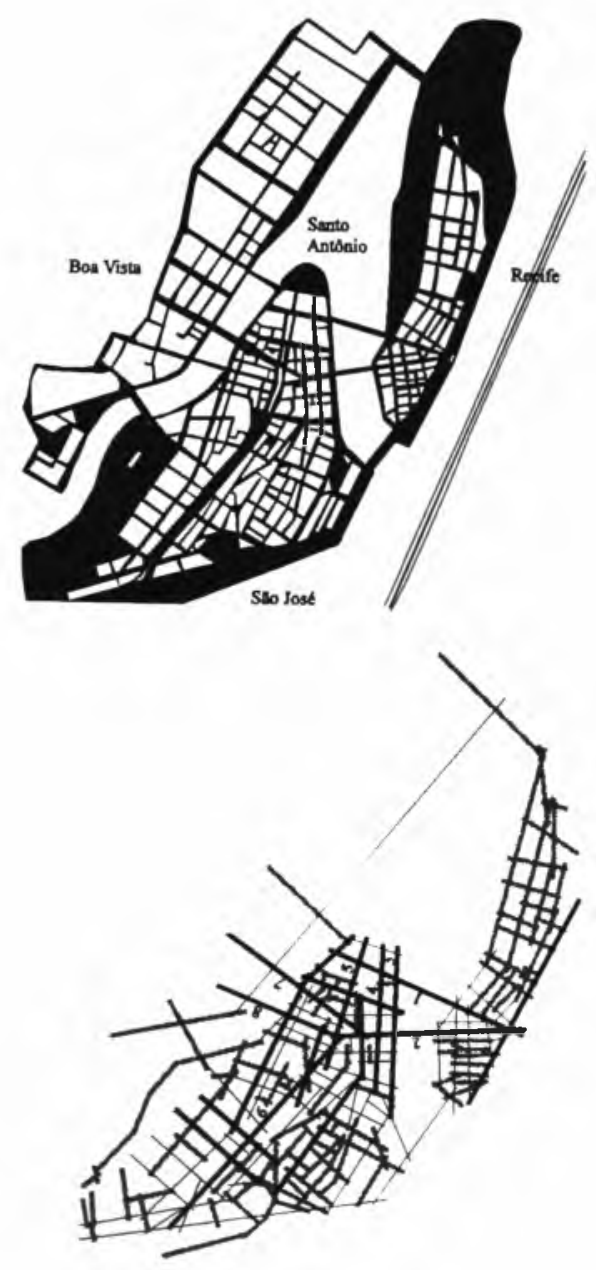
alterações morfológicas que indicam para um outro tipo de leiaute regionalizado, no qual surge a estruturação de subcentros (Peponis, 1989, p. 43); a redução dos valores de força do núcleo de integração confirma esta alteração;

d) as transformações físicas que a área apresentou ao longo do tempo não alteraram significativamente os espaços que compõem o núcleo de integração, e suas relações com o percurso-matriz. As reformas urbanas executadas em Porto Alegre, em geral, conduziram para uma confirmação dos espaços do núcleo de integração, ao mesmo tempo que limitam a força do núcleo de integração inicial.

e) os espaços de maior segregação do tecido considerado poderiam ser classificados em dois tipos principais: os que a partir de reformas urbanas perdem esta característica pela alteração das condições de acessibilidade em relação ao sistema espacial e aqueles que permanecem como espaços mais segregados ao longo do tempo. Neste último caso temos a região sul da península onde, graças a esta relativa segregação em relação ao conjunto do sistema, podemos encontrar uma forte ocupação residencial no centro da cidade, enquanto que esta importante função urbana praticamente desaparece do restante da área, principalmente mais próximo do núcleo de integração.

f) desde o início da sua formação, tanto os espaços públicos mais importantes da cidade - principais praças centrais - como as funções urbanas de maior relevância - administração pública, comércio, serviços, e setor financeiro - tendem a se implantar ao longo e/ou no cruzamento dos espaços de maior integração.

Em relação ao Recife, em todos os momentos analisados é possível identificar a composição multifacetada do tecido urbano, individualizada nos tecidos holandês, português e moderno, permanecendo com suas características sintáticas ao longo do tempo, quais sejam, o núcleo de integração sobreposto ao tecido holandês, é acrescido da cidade moderna, permanecendo o tecido português como a área mais segregada do conjunto.

O percurso-matriz, identificado permanece como eixo estruturador do tecido urbano, mantendo estreita relação com o núcleo de integração e com a matriz elementar, conformando um sistema de consonância entre os termos do processo formativo do tecido atual. A cidade moderna se amalgama com o tecido holandês, concorrendo para a formação de um único núcleo de integração, mais denso e distributivo.

Interessante observar que a relativa segregação dos edifícios religiosos, ainda que localizados na extremidade ou ao longo de linhas mais integradas, ressalta a importância de sua função cerimonial, diferenciando-os por meio da segregação, estabelecendo uma certa descontinuidade entre o espaço da vida cotidiana e o sagrado.

\section{Conclusão}

A análise dos resultados permite identificar de que forma origem e processo de crescimento urbano diferenciados conduzem a individualidades urbanas que a técnica da análise sintática evidenciam. $O$ instrumento de análise utilizado permite explicitar, ainda, como os diferentes leiautes urbanos representam ênfases distintas na concentração / dispersão da centralidade e das funções urbanas. 
No exame do processo tipológico foi possivel individualizar os termos intermediários entre o produto atual e sua matriz, entendendo-os como momentos de um processo formativo. Desta forma, foi possível lidar com duas questões fundamentais para análise do espaço urbano: a) a constituição da centralidade espacial e, b) a diferenciação e articulação das partes locais no seu contexto global. Enquanto centralidade se constitui como ponto de convergência, de destinação coletiva, a identidade das cidades é conferida por diferenciação e articulação de partes locais no contexto global (Peponis, 1989). Fica claro que as intervenções urbanísticas, que tanto Porto Alegre como Recife apresentam na sua formação são, também, criações de acessibilidades, atuando, no entanto, de duas distintas formas: por diferenciação do núcleo em dois subcentros, no caso de Porto Alegre, e por consolidação da matriz elementar, no caso de Recife.

\section{Bibliografia}

CANIGGIA, Gianfranco, MAFFEI, Gian Luigi. Composizione architettonicae tipologia edilizia:lettura dell'edilizzia di base. Venezia: Marsilio Editori, 1981.

EKISTICS, vol. 56, n. 334/335, jan.-fev./mar.-apr., 1989. Número especial - Space syntax: social implications of urban layouts (editor convidado - John Peponis)

HILLIER, B., HANSON, J. The social logic of space. London: Cambridge University Press, 1984

HILLIER, B., HANSON, J., PEPONIS, J. Syntaticanalysis of settlements. Architecture \& Comportment /Architecture \& Behavior. v. 3, n. 3, p. 217-231, 1987.

HILLIER, B. Specifically architectural knowledge. Artigo apresentado em Harvard e a ser publicado em The Harvard Architectural Review, oct. 1990.

HILLIER, B. etal. Natural movement: or, configuration and attraction in urban pedestrian movement. Environment and Planning B: planning and design, v. 20, p. 29-66, 1993.

PEPONIS, J. Espaço, cultura e desenho urbano. Arquiteturae Urbanismo, n. 41, p. 78-83, abr./maio, 1992.

Space, culture and urban design in late modernismand after. EKISTICS, v. 56, n. 334/ 335, p. 93-108, jan./feb./mar./apr. 1989.

PEPONIS, J. et al. The spatial core of urban culture. EKISTICS, v. 56, n. 334/335, p. 43-55, jan.fev./ mar./apr., 1989

TEKLENBURG, J. A. F. TIMMERMANS, H. J. P., WANGENBERG, A. F. van. Space syntax demystified. Artigo apresentado na $12^{\mathrm{a}}$ BIENNAL CONFERENCE OF THE INTERNATIONAL ASSOCIATION FOR PEOPLE-ENVIRONMENT STUDIES. 11-14 julho 1992. Chalkidiki, Grécia.

Space syntax: standardised integration measures and some simulations. Artigo apresentado na $22^{\mathrm{a}}$ ANNUAL CONFERENCE OF THE ENVIRONMENTALDESIGN RESEARCH ASSOCIATION. 12-15 março, 1991. Oaxtepec, México.

ZANELLA, Patrizia (ed.) Morfologia dello spazio urbano: questioni di analisi e di progetto. Milano: Franco Angeli, 1988.

\section{Nota}

Os bolsistas Maria Emília Rodrigues Regina, Christian Beulen, do curso de Arquitetura e Urbanismo, Yuri Amorim Monteiro, do curso de Engenharia Mecânica da Universidade Federal de Pernambuco, e Susana Carolina Cordova, de Porto Alegre, participaram deste trabalho. 